\title{
Exploration and Practice on the Teaching Reform of Preparatory Chinese Education in Yili Normal University*
}

\author{
Xiaowei Diao \\ Chinese Language Institute \\ Yili Normal University \\ Yining, China 835000
}

\begin{abstract}
The National Chinese Test (MHK) is a national standardized test for the Chinese proficiency of minority Chinese learners who are not native speakers of Chinese. Through the comparative analysis of the MHK scores and passing rates of the preparatory students of Yili Teachers College, we can find out the problems existing in the preuniversity Chinese education and teaching, so that the targeted reform of the preparatory Chinese education and teaching will help to improve the quality of preparatory Chinese education.
\end{abstract}

Keywords-MHK; Yili Teachers College; preparatory Chinese teaching

\section{INTRODUCTION}

The national Chinese test is divided into two parts: written test and oral test. From the aspects of listening comprehension, reading comprehension, written expression and oral expression, through the combination of subjective questions and objective test questions, the candidates' ability to communicate in Chinese is comprehensively examined. Both the listening and reading tests use objective questions. In the third and fourth exams, the written expression and oral test section were added. Written expression questions cover objectivity, semi-subjectivity and subjective questions. The oral expression test uses subjective questions. [1] Each of the written test (listening, reading, written expression) and the oral test will reach the corresponding score line to obtain the corresponding certificate.

\section{COMPARATIVE ANALYSIS OF MHK SCORES OF PRE-} UNIVERSITY STUDENTS IN YILI NORMAL UNIVERSITY

A. Comparative Analysis of Pass Rate of $M H K$ (Level 3) for 2012-2014 Pre-graduate Students

It can be seen from "Table I" that the second semester of

*Fund Project: Key Research Base of Humanities and Social Sciences in Colleges and Universities of Xinjiang Normal University-Bidding Project of Xinjiang Minority Bilingual Research Center "Study on Teaching Materials for Xinjiang Minority Primary and Secondary SchoolsTaking Yili Prefecture as an Example" (040412C03); Yili Teachers College The key project of education and teaching reform, "Exploration and Practice of the Teaching Reform of Preparatory Chinese Education in Yili Teachers College" (JGZD201402). the MHK (Level 3) score of the 2012 pre-graduate students is significantly improved compared with the first semester. The total number of people who obtained the top three and three B certificates in the first MHK (Level 3) exam was 292. The pass rate was $45.06 \%$. The total number of people who obtained the top three and three B certificates in the second MHK (Level 3) test was 370, and the pass rate was $55.39 \%$. In contrast, the pass rate of the 2012 pre-graduate MHK (Level 3) is increasing.

TABLE I. COMPARISON OF MHK (LEVEL 3) SCORES FOR 2012 PREGRADUATE STUDENTS

\begin{tabular}{|l|l|l|l|l|}
\hline & Three A & three B & $\begin{array}{l}\text { total scores } \\
\geqq 200\end{array}$ & $\begin{array}{l}\text { total scores } \\
<200\end{array}$ \\
\hline $\begin{array}{l}\text { Number of first } \\
\text { semester }\end{array}$ & 120 & 172 & 152 & 204 \\
\hline Proportion of & $18.52 \%$ & $26.54 \%$ & $23.46 \%$ & $31.48 \%$ \\
\hline $\begin{array}{l}\text { Number } \\
\text { second } \\
\text { semester }\end{array}$ & 216 & 178 & 120 \\
\hline Proportion & $23.05 \%$ & $32.34 \%$ & $26.65 \%$ & $17.96 \%$ \\
\hline
\end{tabular}

It can be seen from "Table II": 2013 pre-graduate students: the total number of students who obtained the top three and three certificates in the MHK (Level 3) exam is 275 , the pass rate is $43.24 \%$; the second MHK (Level 3) exam The total number of people receiving the top three and three $\mathrm{B}$ is 370 , and the pass rate is $57.37 \%$. In contrast, the pass rate of the 2013 pre-graduate MHK (Level 3) is increasing.

TABLE II. COMPARISON OF GRADES OF GRAdE 3 PRE-GRAdUATE STUDENTS MHK (LEVEL 3)

\begin{tabular}{|l|l|l|l|l|}
\hline & Three A & three B & $\begin{array}{l}\text { total scores } \\
\geqq 200\end{array}$ & $\begin{array}{l}\text { total scores } \\
<200\end{array}$ \\
\hline $\begin{array}{l}\text { Number of first } \\
\text { semester }\end{array}$ & 110 & 165 & 198 & 163 \\
\hline Proportion of & $17.30 \%$ & $25.94 \%$ & $31.13 \%$ & $25.63 \%$ \\
\hline $\begin{array}{l}\text { Number } \\
\text { second semester }\end{array}$ & 216 & 165 & 110 \\
\hline Proportion & $23.88 \%$ & $33.49 \%$ & $25.58 \%$ & $17.05 \%$ \\
\hline
\end{tabular}


TABLE III. COMPARISON OF 2014 MK (LEVEL 3) GRADES OF PREPARATORY STUDENTS

\begin{tabular}{|l|l|l|l|l|}
\hline & Three A & three B & $\begin{array}{l}\text { total scores } \\
\geqq 200\end{array}$ & $\begin{array}{l}\text { total } \\
\text { scores } \\
<200\end{array}$ \\
\hline $\begin{array}{l}\text { Number of } \\
\text { first semester }\end{array}$ & 82 & 194 & 57 & 148 \\
\hline Proportion & $17.05 \%$ & $40.33 \%$ & $11.85 \%$ & $30.77 \%$ \\
\hline $\begin{array}{l}\text { Number of } \\
\text { second } \\
\text { semester }\end{array}$ & 137 & 213 & 80 & 52 \\
\hline Proportion & $28.42 \%$ & $44.19 \%$ & $16.60 \%$ & $10.79 \%$ \\
\hline
\end{tabular}

It can be seen from "Table III": 2014 pre-graduate students: the total number of people who obtained the top three and three certificates in the MHK (Level 3) exam was 276, the pass rate was 57.38\%; the second MHK (Level 3) test The total number of people who obtained the top three and three certificates was 350 , and the pass rate was $72.61 \%$. In contrast, the $2014 \mathrm{MK}$ (Level 3) pass rate has increased significantly.
TABLE IV. COMParison OF MHK (LeVEl 3) PASS RATE FOR 20122014 PRE-UNIVERSITY STUDENTS

\begin{tabular}{|l|l|l|}
\hline Grade & Three A (pass rate) & Three B (pass rate) \\
\hline $2012(1)$ & $18.52 \%$ & $26.54 \%$ \\
\hline $2012(2)$ & $23.05 \%$ & $32.34 \%$ \\
\hline $2013(1)$ & $17.03 \%$ & $25.94 \%$ \\
\hline $2013(2)$ & $23.88 \%$ & $33.49 \%$ \\
\hline $2014(1)$ & $17.05 \%$ & $40.33 \%$ \\
\hline $2014(2)$ & $28.42 \%$ & $44.19 \%$ \\
\hline
\end{tabular}

It can be seen from "Table IV" that the pass rates of the MHK (Grade 3) exams for the 2012, 2013, and 2014 pregraduate students are both on the rise, indicating that the one-year teaching and MHK (three-level) Intensive training, our preparatory Chinese teaching has achieved certain results.

\section{B. 2012-2014 MHK (Level 3) Single-score Comparison}

TABLE V. MHK (LEVEl 3) Listening COMPREHENSION PARTIAL AVERAGE COMPARISON

\begin{tabular}{|l|l|l|l|l|l|l|}
\hline Level & Grade & Grade & Grade & Grade & Grade & Grade \\
\hline $\begin{array}{l}\text { Top three } \\
\text { hearing) }\end{array}$ & $2012(1)$ & $2012(2)$ & $2013(1)$ & $2013(2)$ & $2014(1)$ & $2014(2)$ \\
\hline Three B (Hearing) & 75.2 & 86.5 & 81.9 & 83.5 & 82.79 & 85.26 \\
\hline $\begin{array}{l}\text { No level (total } \\
\text { score } \\
\geqq 200)\end{array}$ & 64.36 & 64 & no & 73 & 69.38 & 64 \\
\hline $\begin{array}{l}\text { No level (total } \\
\text { score<200) }\end{array}$ & 35 & 38.5 & 43.2 & 42.3 & 31.48 & 34.9 \\
\hline
\end{tabular}

TABLE VI. MHK (LEVEl 3) REAding COMPREHENSION PARTIAL AVERAGE COMPARISON

\begin{tabular}{|l|l|l|l|l|l|l|}
\hline Level & Grade & Grade & Grade & Grade & Grade & Grade \\
\hline Top three (read) & $2012(1)$ & $2012(2)$ & $2013(1)$ & $2013(2)$ & $2014(1)$ & $2014(2)$ \\
\hline Three B (read) & 84.47 & 82.62 & 77.4 & 81.2 & 84.41 & 82.26 \\
\hline $\begin{array}{l}\text { No level (total score } \\
\geqq 200)\end{array}$ & 70.5 & 71.5 & 62.9 & 80.2 & 71 & 71.5 \\
\hline $\begin{array}{l}\text { No level (total score } \\
\text { <200) }\end{array}$ & 34.8 & 36 & 42 & 39.5 & 60.57 & 60.51 \\
\hline
\end{tabular}

TABLE VII. MHK (LEVEL 3) WRITTEN EXPRESSION PARTIAL AVERAGE COMPARISON

\begin{tabular}{|l|l|l|l|l|l|l|}
\hline Level & Grade & Grade & Grade & Grade & Grade & Grade \\
\hline & $2012(1)$ & $2012(2)$ & $2013(1)$ & $2013(2)$ & $2014(1)$ & $2014(2)$ \\
\hline Top three (written expression ) & 76.91 & 78.2 & 81.2 & 82.9 & 75.18 & 78.2 \\
\hline Three B (written expression ) & 63.34 & 65 & 70.9 & 80.5 & 63.3 & 65 \\
\hline $\begin{array}{l}\text { No level (total score } \\
\geqq 200)\end{array}$ & 53 & 52.7 & None & 77 & 53.58 & 52.7 \\
\hline No level (total score <200) & 38 & 44.2 & 48.7 & 46.5 & 33.48 & 39.7 \\
\hline
\end{tabular}

Remarks: Each of the scores in "Table V", "Table VI", and "Table VII" is 100 points. In the first semester of 2013, there was no grade (total score 200) data for some reasons.

From the comparative analysis of the average scores of the 2012-2014 pre-graduate students MHK (level 3), it is seen that the listening comprehension and reading comprehension of the 2012 pre-graduate students have declined after one year of study; the 2013 level of listening comprehension, reading comprehension. In the written expression of the average score, after one year of academic achievement has improved; the average score of listening comprehension and written expression of the 2014 pre- 
graduate students has increased, while the average score of reading comprehension has decreased.

Through comparative analysis of the results, we can see that the Chinese language teaching in the preparatory school has achieved certain results, and the passing rate of MHK (level 3) has improved. This is the result of the joint efforts of teachers and students, but it also reflects certain in the preparatory Chinese teaching. The problems such as the improvement of students' reading speed and comprehension ability are not obvious, and the writing skills are not solid, which leads to the improvement of individual students' performance or the lack of corresponding certificates in the preparatory stage.

\section{The Status QuO AND PROBlems ANALysis OF PRE- UNIVERSITY CHINESE EDUCATION}

\section{A. Focusing on Experience, and Ignoring Research}

In the teaching, it is found that the current preparatory Chinese teaching has problems of heavy experience and light research. In the teaching process, teachers generally pay more attention to the choice of Chinese textbooks, pay attention to the understanding of the course content and prepare lessons, but do not further understand the rules and methods of Chinese teaching, and do not fully combine the characteristics of minority preparatory students to carry out corresponding Teaching activities, many pre-university teachers always think that as long as you choose a good teaching material, the content you want to talk about can improve the quality of teaching. In the teaching process, teachers pay more attention to the explanation of sentences or the use of words in the teaching process. Content, which allows teachers to have certain teaching experience in practice, however, these teaching experiences cannot meet the needs of minority preparatory students, because each minority preparatory student has individual differences, and their ability to accept knowledge and understand knowledge is different.

\section{B. Emphasis on Knowledge Transfer and Light Chinese Practice}

In the setting of the preparatory Chinese teaching curriculum, there are problems of heavy knowledge transfer and light language practice. Because in the teaching process, teachers attach great importance to the amount of knowledge students have in order to cope with the MHK (Level 3) exam. By understanding, students are not satisfied with the current Chinese teaching. Only some students said that the teaching effect is better, and they have a very big help to themselves. Some students have a moderate response, and there is no current Chinese curriculum. Approved, I believe that this kind of teaching effect is general, a small number of students clearly indicate that the teaching effect is not satisfactory, and some students said that the current Chinese teaching pays too much attention to the teaching of knowledge, ignoring the cultivation of the ability to use Chinese.

\section{Re-use, Light Training}

There is a problem of heavy use and light training in the preparatory Chinese teaching. For pre-university Chinese teachers, they are under high-pressure work for a long time, and work and scientific research tasks are heavy. There is no time for further study and study, and there is no systematic training. Especially at present, the training and training of Chinese teachers are still in the exploratory stage, and there are a series of problems that need to be studied in depth. These problems and difficulties lack theoretical guidance [2]. In the teaching practice, it is also found that some Chinese teachers still have ideas and ideas that do not need further study and improvement. They believe that the preparatory Chinese teaching work is very simple. Most of the explanations are basic knowledge, and there is no need to go out for training and further training. Under this erroneous view and ideological understanding, the pre-university Chinese teaching lacks new ideas, new methods and new means, and it is impossible to construct a Chinese teaching method and system that is suitable for minority students. As a result, the preparatory Chinese teaching has always stagnated, and there is no big one. Break through and leap.

\section{Re-planning and Light Implementation}

Through teaching practice, it is found that pre-university Chinese teaching has problems that are planned and implemented lightly. The school has set up the corresponding examination plan according to the syllabus. However, from the teaching practice of 2012-2014 students, the number of MHK (level 3) pass rates has increased year by year, but the single subject scores are not normally distributed. The implementation effect is not good. The reason is that the papers used in the past three years are relatively old, and when the exam is over, the MHK exam papers are directly destroyed. In this case, the students only know their own achievements, and the teachers cannot analyze the papers in depth. The degree of easiness and regularity, the same as the college English CET-6 and the college entrance examination are different from the MHK test. After the test is completed, the test papers will be published online. Students can recall the wrong questions and learn the lesson.

\section{REFORM PATH OF CHINESE EDUCATION TEACHING IN PREPARATORY SCHOOL}

\section{A. Strengthen Relevant Theoretical Research}

Under the new development situation, it is necessary to further strengthen the research on relevant theories and strive to increase the proportion of scientific research in the assessment of Chinese teachers' work. Schools and teachers should fully understand the difference between preparatory Chinese teaching and other disciplines. It is necessary to study specific objects and scope. At the same time, it should also conduct in-depth research on the basic theories and basic laws of preparatory Chinese teaching, effectively changing the problem of theoretical research lag. Teaching activities are guided by more systematic and scientific theories. In addition, from the actual situation, the pre- 
university Chinese teaching has a strong experience-based teaching phenomenon, and it is particularly important to further enhance the proportion of scientific research in Chinese teachers' business assessment and job evaluation.

\section{B. Clarify the Guiding Ideology of Teaching Work}

It is necessary to further clarify the guiding ideology of teaching, analyze the objectives of preparatory Chinese teaching in depth, establish the guiding ideology suitable for minority preparatory students, and guide the practical work with more scientific and systematic theoretical knowledge to provide some support for the development of preparatory Chinese teaching. In addition, it is necessary to clarify the long-term teaching objectives, change the teaching guidance thoughts based on theoretical teaching, pay more attention to improving students' practical ability in Chinese practice, improve relevant theoretical systems, and constantly deepen the reform of preparatory teaching. Only in this way can we have targeted theories to guide the preparatory Chinese teaching activities and improve the quality of teaching.

\section{Change the Language Concept}

The language concept, that is, the language attitude, is an important factor affecting Chinese education. Minority students are the subject of our teaching. Their bilingual attitude is directly related to their psychological and behavioral and learning effects in learning and using their mother tongue and Chinese. Therefore, in order to improve the teaching of preparatory Chinese, it is necessary to deeply understand the language attitudes of minority students, accurately grasp their understanding and views on mother tongue, Chinese, and bilingual, timely change their wrong language concepts, and publicize some of the language of the party. The cultural guidelines and policies solve their language concepts from the heart and lay the foundation for a better study of Chinese.

\section{Improve the Preparatory Chinese Course Setting}

In order to more effectively meet the needs of preparatory Chinese teaching, we should further improve the preparatory Chinese curriculum, so that the curriculum can meet the actual needs and meet the needs of the preparatory minority students. Therefore, experts should be organized to combine the training objectives and talent specifications of colleges and universities, to analyze the current situation of minority students' students, and to conduct in-depth research and evaluation of minority students. According to the objective actual situation, try to implement small class teaching, improve the rationality of the curriculum arrangement, reduce the workload of teachers, and better meet the needs of the preparatory students. At the same time, it is necessary to fully combine the preparatory Chinese language learning to lay the foundation for professional study. The preparatory Chinese teaching will be carried out from the level of Chinese proficiency test, and gradually change to meet the needs of professional learning. Actively organize experts and scholars to conduct in-depth research on the preparatory Chinese curriculum for ethnic minorities. And assessment, analysis of existing problems, effective adjustment of unscientific courses, and then closely integrated with professional learning. At the same time, according to the actual needs, the two-year preparatory teaching can be implemented to enable minority students to learn the basics of Chinese while learning Chinese, and lay a solid foundation for them to enter the professional class.

\section{E. Improve Teaching Concepts and Teaching Methods}

First of all, we should change the teaching concept and make full use of the second classroom. The knowledge of teaching classrooms has certain limitations. Therefore, preuniversity Chinese teaching should open up new classrooms as much as possible, break the limitations of traditional classrooms, let students go out, have more opportunities to communicate and communicate with others in Chinese, and then improve students' ability to express and use Chinese. At the same time, teachers can make full use of multimedia technology to implement micro-teaching, flip classrooms or use resources such as the Internet to develop teaching content, expose students to more knowledge, expand the space for preparatory Chinese teaching activities, and provide students with more extensive exposure to Chinese knowledge. And culture, understand the characteristics of Chinese, and improve their interest and motivation in learning Chinese.

Secondly, it is necessary to further improve the test skills of students MHK (Level 3). The MHK (Level 3) test is a national-level professional test, and the test content has a certain orientation. Reasonably set the teaching method and teaching content in the teaching process, pay attention to improve the test skills of students MHK (Level 3), to better guide students to learn, to make clear the direction of learning, and improve the students' effect. In this process, teachers should further strengthen their understanding of the MHK vocabulary outline and grammar outline, and improve the teaching content by analyzing the vocabulary and knowledge points of the outline.

Third, effective implementation of mixed accommodation between the people and the Han, so that minority students can increase their opportunities for communication and exchange with Han students, better use Chinese to communicate, and improve the practical ability of language knowledge. At the same time, in the process of contact with Han students, minority students can also understand the communication and communication methods of Chinese and strengthen their listening skills.

\section{CONCLUSION}

The preparatory Chinese teaching activity is a teaching mode set up for the problem of minority students' Chinese proficiency. It aims to rapidly improve the Chinese language ability of minority students, so that they can better communicate and communicate in future study and work. The purpose of implementing pre-university Chinese teaching in our school must also reach three levels: First, the purpose of the language - to teach students how to learn and master Chinese. Second is the purpose of education - to improve the quality of national education. Third is the social 
purpose to promote the development and prosperity of the nation and the harmonious progress of Xinjiang society [4]. It can be seen that the preparatory Chinese teaching activities are very important for minority students.

\section{REFERENCES}

[1] Zhang Fenglin. Introduction to Chinese National Minority Chinese Proficiency Test (MHK)[J]. Journal of Yan Bian Education College, 2004(5): 78.

[2] Li Ruzhong. The tenth theory of bilingual education [M]. Urumqi: Xinjiang People's Publishing House, 2012: 160.

[3] Li Ruzhong, He Xianghong. Collection of bilingual education research in Xinjiang (2) [M]. Urumqi: Xinjiang People's Publishing House, 2010: 3 .

[4] Li Ruzhong. The tenth theory of bilingual education [M]. Urumqi: Xinjiang People's Publishing House, 2012: 38 